\title{
A phosphorylation-acetylation switch regulates STAT1 signaling
}

\author{
Oliver H. Krämer, ${ }^{1,6}$ Shirley K. Knauer, ${ }^{2}$ Georg Greiner, ${ }^{1}$ Enrico Jandt, ${ }^{1}$ Sigrid Reichardt, ${ }^{1}$ \\ Karl-Heinz Gührs, ${ }^{3}$ Roland H. Stauber, ${ }^{2}$ Frank D. Böhmer, ${ }^{4}$ and Thorsten Heinzel ${ }^{1,5}$

\begin{abstract}
${ }^{1}$ Institute of Biochemistry and Biophysics, Center for Molecular Biomedicine (CMB), University of Jena, 07743 Jena, Germany; ${ }^{2}$ Department of Molecular and Cellular Oncology, University Hospital of Mainz, 55101 Mainz, Germany; ${ }^{3}$ Leibniz-Institute for 07743 Jena, Germany
\end{abstract} \\ Age Research, Fritz-Lipmann-Institute (FLI), 07743 Jena, Germany; ${ }^{4}$ Institute of Molecular Cell Biology, CMB, University of Jena,
}

Cytokines such as interferons (IFNs) activate signal transducers and activators of transcription (STATs) via phosphorylation. Histone deacetylases (HDACs) and the histone acetyltransferase (HAT) CBP dynamically regulate STAT1 acetylation. Here we show that acetylation of STAT1 counteracts IFN-induced STAT1 phosphorylation, nuclear translocation, DNA binding, and target gene expression. Biochemical and genetic experiments altering the HAT/HDAC activity ratio and STAT1 mutants reveal that a phospho-acetyl switch regulates STAT1 signaling via CBP, HDAC3, and the T-cell protein tyrosine phosphatase (TCP45). Strikingly, inhibition of STAT1 signaling via CBP-mediated acetylation is distinct from the functions of this HAT in transcriptional activation. STAT1 acetylation induces binding of TCP45, which catalyzes dephosphorylation and latency of STAT1. Our results provide a deeper understanding of the modulation of STAT1 activity. These findings reveal a new layer of physiologically relevant STAT1 regulation and suggest that a previously unidentified balance between phosphorylation and acetylation affects cytokine signaling.

[Keywords: STAT1; acetylation; phosphorylation; histone deacetylase; interferon; HDAC inhibitor; phosphatase TCP45]

Supplemental material is available at http://www.genesdev.org.

Received March 11, 2008; revised version accepted November 20, 2008.

The STAT signaling pathway is a paradigm for ligandinduced signaling from the cell surface to the nucleus. Cytokines and growth factors activate the transcription factor STAT1, which regulates the expression of physiologically important genes for cell growth, differentiation, apoptosis, and immune functions. Interferons (IFNs) are cytokines that induce dimerization of their cognate receptors leading to phosphorylation-dependent activation of the receptor-associated tyrosine kinases JAK1/2 and TYK2. These phosphorylate the C-terminal tyrosine residues $\mathrm{Y}^{701}$ in STAT1 and $\mathrm{Y}^{690}$ in STAT2. Subsequently, STAT1 homodimers or STAT1/STAT2 heterodimers reciprocally interacting via their Src homology 2 (SH2) domains rapidly accumulate in the nucleus and induce STAT1 target genes (Ihle 2001; Platanias 2005; Stark 2007).

Receptor internalization, decreased kinase activity, and sumoylation of STAT1, SOCS, and PIAS proteins; as well as STAT1 dephosphorylation by phosphatases (PTPs)

Corresponding authors.

${ }^{5}$ E-MAIL T.Heinzel@uni-jena.de; FAX 49-3641-949352.

${ }^{6}$ E-MAIL Oliver.Kraemer@uni-jena.de; FAX 49-3641-949352.

Article is online at http://www.genesdev.org/cgi/doi/10.1101/gad.479209. followed by nuclear export counteract in vivo responses to IFN (Lim and Cao 2006; Kim and Lee 2007). The PTP Tcell protein tyrosine phosphatase (TCP45) dephosphorylates nuclear STAT1, which recycles STAT1 back to the cytoplasm (ten Hoeve et al. 2002). TCP45 additionally provides latency to previously activated STAT1 independent of the kinase and receptor status in vivo (Sakamoto et al. 2004b). However, the "timer" setting inactivation of phosphorylated nuclear STAT1 remains an enigma.

External as well as internal signals can induce the association of substrates with histone acetyltransferases (HATs) and histone deacetylases (HDACs) controlling the specificity and level of acetylation-dependent protein functions. Acetylation of histones mediated by HATs is a prerequisite for STAT1-dependent transcription (Paulson et al. 2002; Kouzarides 2007). Phosphorylated, nuclear STAT1 transiently binds the HAT CBP (Zhang et al. 1996), which can exist in a complex with the coactivator p/CIP. CBP cannot compensate a lack of p/CIP, which makes it difficult to define individual roles of these factors (Torchia et al. 1997). Recent data demonstrate that association of CBP with STAT1 and acetylation of histones at STAT1 target genes are temporally separated processes (Christova et al. 2007; Ramsauer et al. 2007). 
Strikingly, STAT1-CBP complex formation can even correlate with reduced histone acetylation (Nusinzon and Horvath 2003). Moreover, a STAT1 mutant that is unable to recruit CBP to chromatin still supports IFNdependent transcription (Ramsauer et al. 2007). In agreement with such findings, IFN-dependent activation of STAT1 target genes requires GCN5 rather than CBP/p300 (Paulson et al. 2002).

Apart from tyrosine-phosphorylation, other functionally important post-translational modifications of STAT1 were identified (Lim and Cao 2006; Kim and Lee 2007). Recently, we described that CBP-mediated acetylation of STAT1 depends on the $\varepsilon$-amino group of lysine residues $\mathrm{K}^{410}$ and $\mathrm{K}^{413}$ (Krämer et al. 2006), which belong to the surface-exposed DNA-binding domain (DBD) common to all STATs. Dynamic acetylation of STAT1 is consistent with its interaction with both, HATs and HDACs. Remarkably, data from biochemical and genetic experiments show that HDAC activity is necessary for IFNinduced STAT1 activation (Nusinzon and Horvath 2003; Chang et al. 2004; Klampfer et al. 2004; Sakamoto et al. 2004a; Zupkovitz et al. 2006; Vlasáková et al. 2007). However, it is not clear whether HDACs and HDAC inhibitors (HDACis) affect STAT1 activity directly or by modulating other factors involved in STAT1 signaling.

Here we provide a mechanistic basis for the negative role of STAT1 acetylation in cytokine signaling. Following rapid activation of STAT1 via IFN, acetylation of STAT1 sets the timer for STAT1 inactivation via complex formation between acetylated STAT1 and the PTP TCP45. HDAC3 deacetylates STAT1, thus permitting phosphorylation and restimulation. Reversible, dynamic acetylation hence switches STAT1 between different functional modes. Our data provide novel insights into the covalent modification cycle, which limits the duration of the cytokine signal.

\section{Results}

Acetylation of STAT1 inhibits IFN-dependent STAT1 phosphorylation and nuclear translocation

IFNs can induce phosphorylation as well as acetylation of STAT1 in vitro and in vivo (Krämer et al. 2006; Hayashi et al. 2007; Tang et al. 2007). We examined the kinetics of STAT1 phosphorylation and acetylation in $293 \mathrm{~T}$ cells treated with the type I interferon IFN $\alpha$. Our data demonstrate that STAT1 acetylation follows STAT1 phosphorylation, and we found a correlation between STAT1 acetylation and dephosphorylation (Fig. 1A). Furthermore, using stringent immunoprecipitation (IP) conditions, we noted that acetylation and phosphorylation can transiently occur simultaneously on STAT1 (Fig. 1B). To evaluate the functional consequences of STAT1 acetylation, we analyzed whether a previous exposure to IFN $\alpha$ affects STAT1 phosphorylation. We found that, independent of ongoing protein synthesis or degradation and irrespective of the type of IFN and its cognate receptor, STAT1 could not be phosphorylated in re-exposed cells (Fig. 1C,D; Supplemental Fig. S1A), which confirms pre- vious observations (Sakamoto et al. 2004a). If STAT1 acetylation contributes to this process, HDACis should equally prevent STAT1 phosphorylation. Indeed, consistent with a previous report (Klampfer et al. 2004), pretreatment with HDACis inhibited IFN $\alpha$ - or IFN $\gamma$-induced STAT1 phosphorylation in 293T, SK-Mel-37, and 2fTGH cells (Fig. 1E; data not shown). We could confirm such results in the presence of a caspase inhibitor or with MCF7 cells resistant to apoptosis induced by HDACis (Supplemental Fig. S1B,C; Krämer et al. 2008a). Thus, acetylation-dependent inactivation of STAT1 occurs independently of apoptosis. Furthermore, in agreement with the slow kinetics of HDACi-induced STAT1 acetylation (Krämer et al. 2006), coadministration of HDACi and IFN did not affect the extremely rapid IFN-induced phosphorylation of STAT1 (Fig. 1F), but accelerated its dephosphorylation. Delayed acetylation of STAT1 in the absence of IFN presumably stems from very low levels of nuclear STAT1 able to interact with CBP residing in the nucleus (Zhang et al. 1996; Meyer et al. 2003; Krämer et al. 2006). Consistently, short-term incubation with IFN $\alpha$ did not evoke STAT1 acetylation (Supplemental Fig. S1D). STAT1 acetylation correlates with its nuclear shuttling and time-delayed cytoplasmic accumulation of CBP (Krämer et al. 2006).

To fully exclude nonspecific effects exerted by HDACi and to demonstrate the effect of STAT1 acetylation sites on phosphorylation, we transfected STAT1null U3A cells and HeLa cells with vectors encoding wild-type or mutated STAT1. These mutants harbor lysine-to-glutamine $\left(\mathrm{Q} ; \operatorname{STAT} 1^{\mathrm{K} 410,413 \mathrm{Q}}\right)$ or arginine $\left(\mathrm{R}_{\text {; }}\right.$ STAT $1^{\mathrm{K} 410,413 \mathrm{R}}$ ) exchanges in the potential STAT1 acetylation sites $\mathrm{K}^{410}$ and $\mathrm{K}^{413}$, which mimic the acetylated or nonacetylated state of STAT1, respectively (Krämer et al. 2006; Supplemental Fig. S1E). We found that upon stimulation with IFN $\alpha$, STAT $1^{\text {K410,413R }}$ became phosphorylated and accumulated in the nucleus just like wild-type STAT1. However, STAT1 ${ }^{\mathrm{K} 410,413 \mathrm{Q}}$ remained unphosphorylated and did not undergo nuclear translocation (Fig. 1G,H; Supplemental Fig. S1F). Consistently, STAT1 and STAT $1^{\mathrm{K} 410,413 \mathrm{R}}$, although not STAT $1^{\mathrm{K} 410,413 \mathrm{Q}}$, bound Importin $\alpha 5$ (Fig. 1I) mediating nuclear transport of phosphorylated STAT1 (Sekimoto et al. 1997; Melén et al. 2001).

STAT1 DNA-binding mutants do not accumulate in the nucleus because of their rapid export via a leptomycin B (LMB)-sensitive CRM1-dependent mechanism (Meyer et al. 2003). We tested the effect of LMB on nuclear accumulation of STAT1. Whereas wild-type STAT1 was retained in the nucleus after stimulation with IFN and LMB, no increase of STAT $1^{\mathrm{K} 410,413 \mathrm{Q}}$ in the nucleus was detectable under such conditions (Supplemental Fig. S1G). Hence, upstream events such as decreased phosphorylation appear responsible for the latency of pseudoacetylated STAT1. The resistance of acetylated STAT1 to IFN $\alpha$ is unlikely to be caused by decreased interactions with the IFN $\alpha$ receptor (IFNAR) or kinases, since wildtype STAT1 and STAT $1^{\text {K410,413Q }}$ equally colocalized with these factors, and both coprecipitated with the IFNAR (Fig. 1J,K; Krämer et al. 2006). 
A
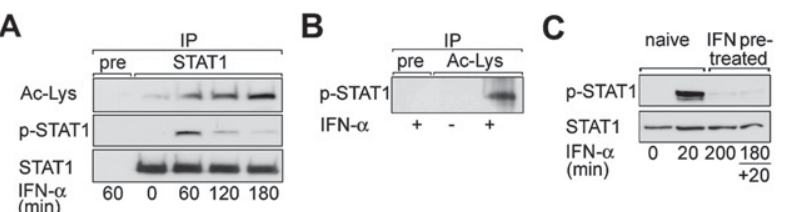

E
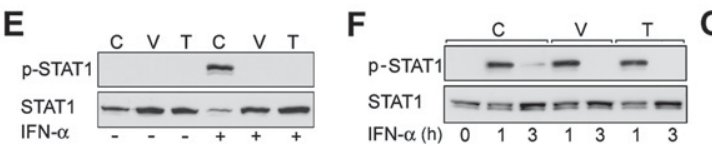

G-STAT
STAT1
IFN- $\alpha$

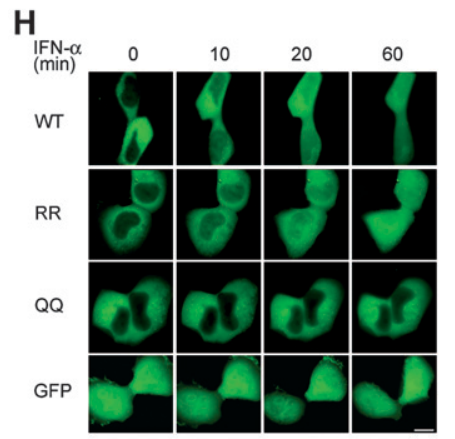

J
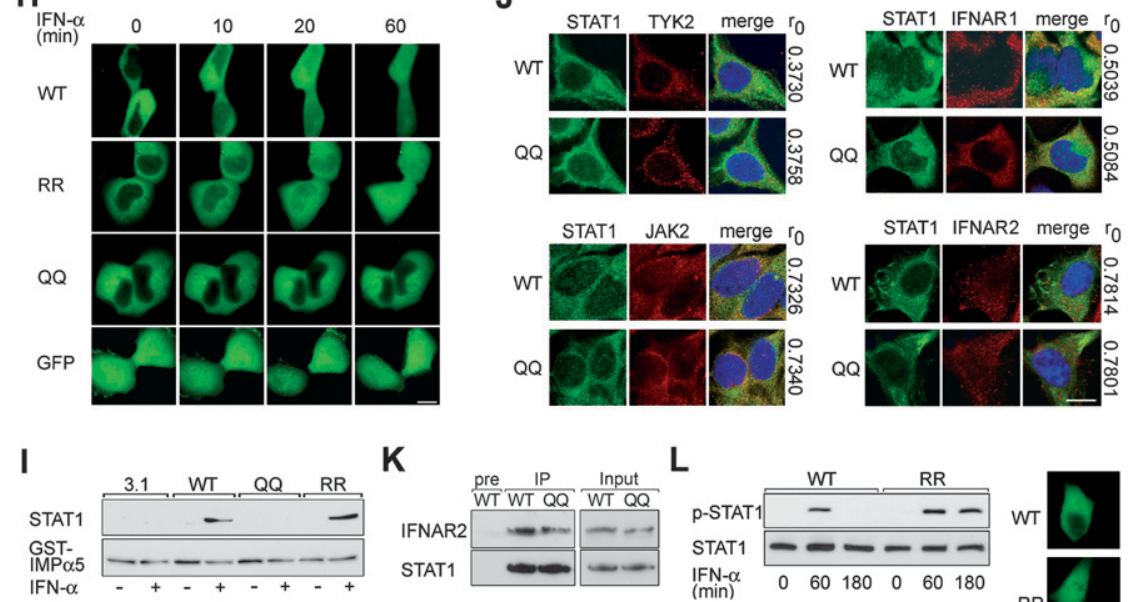

K

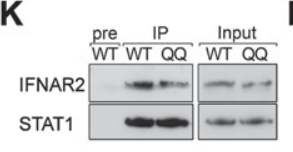

$\mathbf{L}$
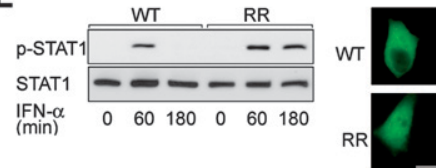

M
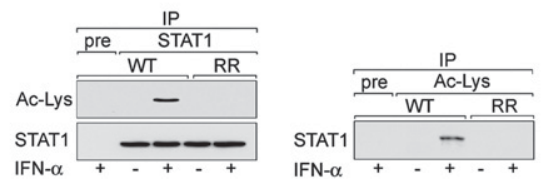

$\mathbf{N}$

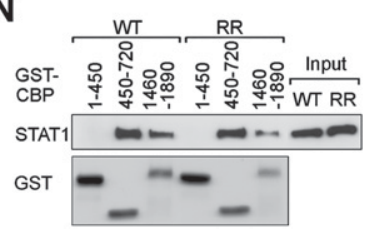

Figure 1. Acetylation affects IFN $\alpha$ induced phosphorylation and translocation of STAT1. (A) STAT1 was immunoprecipitated from lysates of $293 \mathrm{~T}$ cells treated with IFN $\alpha$ for the time periods indicated. Acetylation, phosphorylation, and precipitation of STAT1 were analyzed by Western blot; (IP) immunoprecipitation; (pre) preimmune serum IP. STAT1 phosphorylation was analyzed with an antibody specifically recognizing STAT1 phosphorylated at $\mathrm{Y}^{701}$ in this and all following experiments when indicated. (B) 293T cells were incubated with IFN $-\alpha$ for 40 min (+). Anti-acetyllysine IPs formed under stringent conditions with RIPA buffer (1\% SDS) were analyzed for the presence of $\mathrm{pY}^{701}$-STAT1 by Western blot (IP with control IgG). (C) $293 \mathrm{~T}$ cells were incubated with IFN $\alpha$ for 20 min or remained untreated (0). One-hundred-eighty minutes later, cells were restimulated for 20 $\min (180+20 \mathrm{~min})$. Parallel cultures were kept naive and treated with IFN $\alpha$ for only $20 \mathrm{~min}$. Cell lysates were probed for STAT1 phosphorylation and expression in Western blot. $(D)$ As in $C$, except that the protein/RNA synthesis inhibitors Cycloheximide (CHX) and Actinomycin D (ActD), or the proteasomal inhibitor MG132 , had been added $1 \mathrm{~h}$ before initial IFN treatment. (E) $293 \mathrm{~T}$ cells were incubated with HDACi [(V) VPA; (T) TSA] or left untreated (C). Twenty-four hours later, cells were stimulated with IFN $\alpha$ for 20 $\min (+)$. Lysates were analyzed as in $C .(F)$ 293 T cells were coincubated with IFN $\alpha$ and HDACi for up to $3 \mathrm{~h}$. Lysates were analyzed as in $C$. $(G)$ U3A cells were transfected with DNA for STAT1 (WT), lysine mutants $\mathrm{K}^{410,413 \mathrm{Q}}(\mathrm{QQ}), \mathrm{K}^{410,413 \mathrm{R}}$ (RR), or empty vector pcDNA3.1 (3.1); (2f) 2fTGH, STAT1-positive U3A parental cell line. Forty-eight hours later, IFN $\alpha$ was added to the cells for $1 \mathrm{~h}(+)$. The Western blot was probed as indicated. $(H)$ Translocation of EGFP-STAT1 (WT) and indicated $\mathrm{K}^{410,413}$ mutants was assessed by live cell time-lapse fluorescence microscopy. Transfected U3A cells were treated with IFN $\alpha$ for 0-60 min. In this and all following microscopy experiments, the bar corresponds to $10 \mu \mathrm{m}$ if not stated otherwise. (I) Binding of STAT1 (WT/QQ/RR) to Importin $\alpha 5$ was analyzed by GST pull-down with lysates of transfected U3A cells. Western blots were probed for STAT1 and GST-Importin $\alpha 5$. Cells were treated for $1 \mathrm{~h}$. Pull-down with GST alone did not precipitate STAT1 (not shown). (J) Confocal immunofluorescence microscopy shows colocalization of transfected wild-type (WT) and pseudo-acetylated STAT1 (QQ) with endogenous TYK2, JAK2, or IFNAR1/2 in U3A cells (numbers state "overlap equation" $\left.\mathrm{r}_{0}\right)$. (K) Wild-type STAT1 and $\mathrm{K}^{410,413 \mathrm{Q}}$ were equally recovered in IFNAR2 IPs formed from lysates of transfected U3A cells. $(L)$ U3A cells were transfected with plasmids for STAT1 (WT) or STAT1 ${ }^{\text {K410,413R }}$ (RR). The time course of STAT1 phosphorylation and expression, and IFN-induced nuclear translocation of EGFP-tagged STAT1 (WT/RR) was analyzed 180 min after IFN stimulation. $(M)$ U3A cells were transfected with DNA for STAT1 (WT) or STAT1 ${ }^{\mathrm{K} 410,413 \mathrm{R}}$ (RR). Forty-eight hours later, IFN $\alpha$ was added for $3 \mathrm{~h}(+)$. Lysates were prepared under conditions disrupting protein-protein interactions (1\% SDS). IPs formed with anti-STAT1 or antiacetyllysine antibodies were probed for acetyllysine and STAT1, or STAT1, respectively. (N) GST pull-downs with the indicated fragments of CBP on lysates of U3A cells reconstituted with STAT1 or STAT1 ${ }^{\text {K410,413R }}$ by Western blot against STAT1 or GST.

Further evidence that acetylation allows dephosphorylation of STAT1 is provided by STAT $1^{\mathrm{K} 410,413 \mathrm{R}}$ exhibiting delayed deactivation kinetics with prolonged phosphorylation and nuclear localization after IFN stimulation (Fig. 1L). Additionally, IFN-induced phosphorylation of STAT $1^{\text {K410,413R }}$ was insensitive to a previous exposure to
IFN as well as to HDACi (data not shown). IP of STAT1 or STAT $1^{\text {K410,413R }}$ from reconstituted U3A cells followed by anti-acetyllysine Western blot, as well as the reverse experiment revealed that IFN $\alpha$-induced acetylation of STAT1 is dependent on $\mathrm{K}^{410}$ and $\mathrm{K}^{413}$ (Fig. 1M). Since different interaction of wild-type STAT 1 and STAT $1^{\text {K410,413R }}$ 
with CBP could prevent acetylation of STAT $1^{\text {K410,413R, }}$ we performed a pull-down experiment to demonstrate direct interactions of these proteins (Zhang et al. 1996). Both STAT1 variants equally bound to fragments of CBP containing the two reported STAT1-CBP contact regions (Fig. 1N). These findings strongly indicate that acetylation of STAT1 (likely at lysines $\mathrm{K}^{410}$ and/or $\mathrm{K}^{413}$ ) critically counteracts cytokine-induced STAT1 activation.

\section{Acetylation of STAT1 inhibits IFN-induced STAT1-dependent gene expression}

HDACis have been reported to counteract STAT1 signaling (Nusinzon and Horvath 2003; Chang et al. 2004; Klampfer et al. 2004; Sakamoto et al. 2004a; Vlasáková et al. 2007). To gain insights into the underlying molecular mechanism, we transfected U3A cells with vectors for STAT1 or $\mathrm{K}^{410}, \mathrm{~K}^{413}$ mutants and a GAS-luciferase reporter plasmid harboring promoter elements of IFN $\alpha$ responsive STAT1 target genes subject to induction by an activated STAT1 homodimer (Torchia et al. 1997; Platanias 2005). Wild-type STAT1 potently activated this reporter after IFN $\alpha$ stimulation. STAT1 ${ }^{\mathrm{K} 410,413 \mathrm{R}}$ activated IFN-dependent transcription even more robustly, whereas $\mathrm{STAT1}^{\mathrm{K} 410,413 \mathrm{Q}}$ failed to induce reporter activity (Fig. 2A).

By quantitative real-time PCR, we determined the expression of the IFN $\alpha$-induced, endogenous STAT1 target genes isg 15 and $u b c H 8$ in U3A cells stably transfected with vectors for STAT1. ISG15 and UBCH8 play important roles in the immune response and in several cancers (Dao and Zhang 2005; Krämer et al. 2008b; Okumura et al. 2008), and these genes are induced by an activated STAT1/STAT2 homodimer binding to an ISRE sequence
Figure 2. Lysines 410 and 413 of STAT1 control IFNinduced transcription. (A) A luciferase assay with a GASLuc construct quantifies transcriptional activity of the indicated STAT1 variants in U3A cells. IFN $\alpha$-induced $(24$ h) reporter activation by wild-type STAT1 is set as $100 \%$. Lysates were analyzed for STAT1 expression; (WT) wildtype; (QQ) STAT1 ${ }^{\mathrm{K} 410,413 \mathrm{Q}}$; (RR) STAT1 ${ }^{\mathrm{K} 410,413 \mathrm{R}}$; (3.1) empty vector pcDNA3.1. In this and all following luciferase experiments, luciferase activity is normalized to $\beta$-Gal activity. ( $B)$ IFN $\alpha$-induced ( $8 \mathrm{~h}$ ) expression of the indicated STAT1 target genes was analyzed by quantitative RT-PCR with RNAs from G418-resistant U3A cells stably expressing indicated STAT1 constructs or GFP. Fold induction relates to corresponding untreated cells. The Western blot verifies equal STAT1 expression. $(C)$ Lysates from U3A cells transfected and stimulated as in $A$ were analyzed for $\mathrm{UBCH} 8$ expression. (D) ABCD assay showing STAT1-DNA complex formation. U3A cells were transfected as in $A$ and treated with IFN $\alpha$ for $1 \mathrm{~h}$; (GRE) control oligonucleotide. The Western blot was probed as indicated. (E) Translocation of EGFP$\mathrm{STAT}^{\mathrm{K} 410 \mathrm{Q}}$ or EGFP-STAT1 ${ }^{\mathrm{K} 413 \mathrm{Q}}$ was assessed in U3A cells by live cell time-lapse fluorescence microscopy. Cells were treated with IFN $\alpha(0-60 \mathrm{~min}) .(F)$ STAT1 (WT), STAT1 $1^{\mathrm{K} 410 \mathrm{Q}}$, or STAT1 ${ }^{\mathrm{K} 413 \mathrm{Q}}$ was expressed in U3A cells. Cells were stimulated with IFN for $1 \mathrm{~h}(+)$. (Top panel) STAT1 phosphorylation and expression were determined by Western blot. (Bottom panel) Binding to Importin $\alpha 5$ was analyzed by GST pull-down and Western blot. $(G)$ Luciferase assay results (GAS-Luc) obtained with U3A cells transfected with STAT1 harboring individual or combined $\mathrm{K}$ to $\mathrm{Q}$ and/or $\mathrm{R}$ exchanges of $\mathrm{K}^{410}$ / $\mathrm{K}^{413}$. (H) Expression of UBCH8 in U3A cells transfected with STAT1 constructs stated, was analyzed as in $C$. $(I)$ An ABCD assay shows the DNA binding of wild-type STAT1 (WT), STAT1 ${ }^{\mathrm{K} 410 \mathrm{Q}}$, and STAT1 ${ }^{\mathrm{K} 413 \mathrm{Q}}$ after IFN stimulation.
A

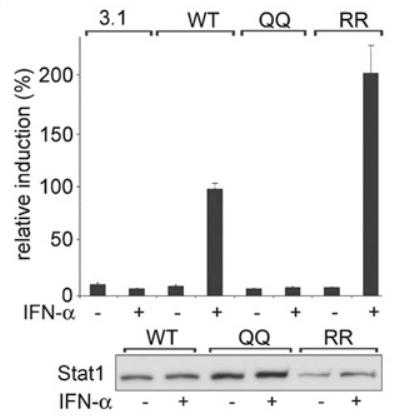

C

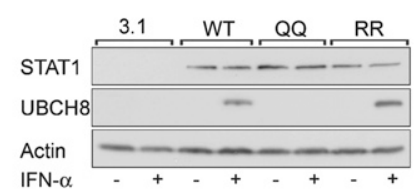

D

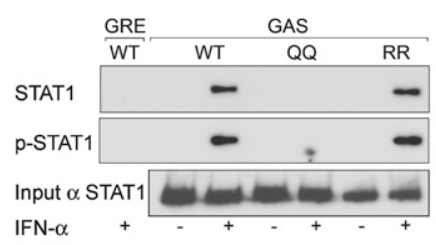

$E$

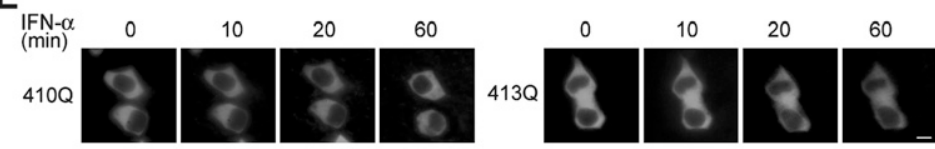

$F$

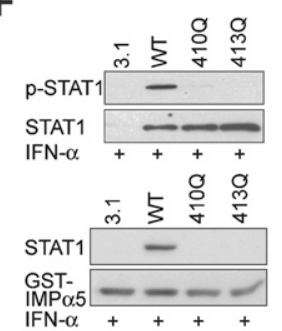

G

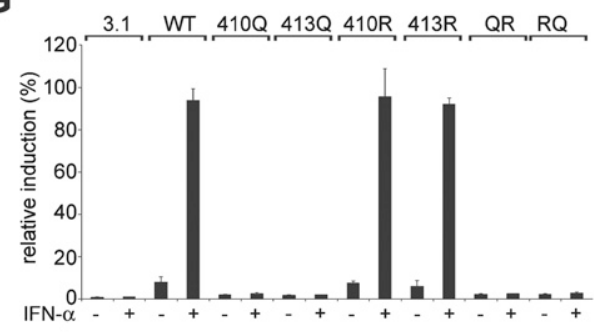

$\mathrm{H}$

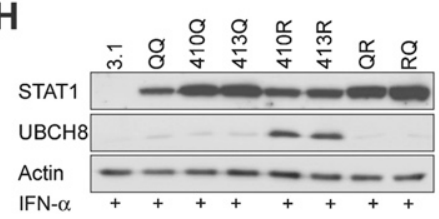

I

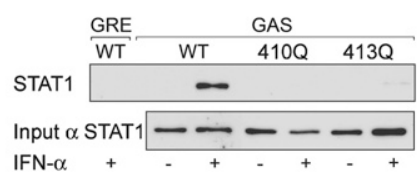


(Nyman et al. 2000; Pfeffer et al. 2004). IFN $\alpha$ strongly enhanced the expression of both genes in STAT1-positive cells. STAT $1^{\mathrm{K} 410,413 \mathrm{R}}$ induced is 15 and $u b c H 8$ even more potently than wild-type STAT1, while STAT $1^{\mathrm{K} 410,413 \mathrm{Q}}$ was unable to mediate significant induction of these genes (Fig. 2B). Western blot analyses showed that this also translates into corresponding $\mathrm{UBCH} 8$ protein levels in U3A cells (Fig. 2C).

Next, we assessed STAT1-DNA complex formation with a GAS consensus oligonucleotide (Meyer et al. 2003). Both STAT1 and STAT1 ${ }^{\mathrm{K} 410,413 \mathrm{R}}$ bound this DNA element upon IFN stimulation (Fig. 2D; Supplemental Fig. S1H). Consistent with all our observations that STAT $1^{\mathrm{K} 410,413 \mathrm{Q}}$ is resistant to IFN $\alpha$, this protein was not recovered with the GAS sequence. To dissect potential site-specific effects, we used STAT1 mutants harboring single K-to-Q exchanges (Supplemental Fig. S1E). STAT $1^{\mathrm{K} 410 \mathrm{R}}$ and STAT $1^{\mathrm{K} 413 \mathrm{R}}$ were responsive to IFN like wild-type STAT1 (data not shown). In contrast, amino acid exchanges mimicking acetylation of $\mathrm{K}^{410} / \mathrm{K}^{413}$ $\left(\mathrm{STAT}^{\mathrm{K} 410 \mathrm{Q}}{ }^{\text {; STAT }} 1^{\mathrm{K} 413 \mathrm{Q}}\right)$ rendered these mutants refractory to IFN $\alpha$. Furthermore, STAT1 with combined $\mathrm{K}$-to-Q and K-to-R mutations demonstrated that a single acetylated $\mathrm{K}^{410} / \mathrm{K}^{413}$ moiety already precludes STAT1 activation (Fig. 2E-I).

Moreover, in 293T cells, phosphorylation of endogenous STAT1 is suppressed by STAT $1^{\mathrm{K} 410,413 \mathrm{Q}}$ in trans (Fig. $3 \mathrm{~A})$. U3A cells restored with STAT1 and STAT1 ${ }^{\mathrm{K} 410,413 \mathrm{Q}}$ recapitulate this finding, as the latter prevents phosphorylation of the wild type (Fig. 3B). Consistent with these data, STAT $1^{\mathrm{K} 410,413 \mathrm{Q}}$, STAT $1^{\mathrm{K} 410 \mathrm{Q}}, \mathrm{STAT}^{\mathrm{K} 413 \mathrm{Q}}$, or HDACi treatment inhibited nuclear signaling and DNA binding of endogenous STAT1 (Fig. 3C-G; data not shown). Our findings indicate that acetylated STAT1 inhibits activation of nonacetylated STAT1 in trans.

Increasing evidence indicates that acetylation negatively affects IFN-induced STAT signaling (Nusinzon and Horvath 2003; Chang et al. 2004; Klampfer et al. 2004; Sakamoto et al. 2004a; Zupkovitz et al. 2006; Vlasáková et al. 2007). Therefore, we asked if our mutant mimicking nonacetylated STAT1 (Fig. 1M) is resistant to HDACi-induced inactivation. We reconstituted U3A cells with wild-type STAT1 and STAT1 ${ }^{\mathrm{K} 410,413 \mathrm{R}}$ and treated these cells with IFN $\alpha$ and VPA. As expected, signaling by wild-type STAT1 was inhibited by acetylation. Expression of ISG15 was inhibited more strongly than UBCH8, which likely results from a complex mechanism by which HDACis induce expression of UBCH8, but not of ISG15 (Krämer et al. 2003; data not shown). In sharp contrast, signaling by STAT $1^{\mathrm{K} 410,413 \mathrm{R}}$ was significantly induced upon inhibition of HDACs (Fig. 3H). These data demonstrate that acetylation per se can promote IFN-induced signaling, whereas acetylation of STAT1 counteracts this process.

Independent of stimulation with IFN, STAT1 dimerizes with other STAT1 or STAT2 molecules (Gupta et al. 1996; Stancato et al. 1996; Braunstein et al. 2003; Mao et al. 2005; Mertens et al. 2006). The trans-dominant-negative effect of STAT1 ${ }^{\mathrm{K} 410,413 \mathrm{Q}}$ (Fig. 3A-G) suggests its dimerization with wild-type STAT1. Co-IP analyses, indeed, demonstrated that HA-tagged STAT1, STAT1 $1^{\mathrm{K} 410,413 \mathrm{Q} \text {, }}$ and STAT $1^{\mathrm{K} 410,413 \mathrm{R}}$ interacted equally well with Flagtagged STAT1 and with endogenous STAT2, independent of K-to-Q mutations in the STAT1 DBD (Fig. 3I-K). Besides being congruent with the observation that HDACis do not affect STAT1 dimerization (Nusinzon and Horvath 2003), our data indicate that the unresponsiveness of acetylated STAT1 and STAT $1^{\mathrm{K} 410,413 \mathrm{Q}}$ to IFN is not just due to a defect in dimerization.

Considering these results and colocalization of STAT1 K410,413Q with STAT2 shown by confocal microscopy (Fig. $3 \mathrm{~L})$, we examined whether STAT $1^{\mathrm{K} 410,413 \mathrm{Q}}$ inhibits STAT2 phosphorylation in trans. IFN $\alpha$ still induced STAT2 phosphorylation in the presence of STAT $1^{\mathrm{K} 410,413 \mathrm{Q}}$ (Fig. 3M), demonstrating that mimicking acetylation of STAT1 at these lysine residues inactivates specifically STAT1.

A recent report shows acetylation of STAT3 at $\mathrm{K}^{685}$ (Yuan et al. 2005) corresponding to $\mathrm{K}^{679}$ in STAT1 (Supplemental Fig. S1I). Acetylation of STAT1 at this site in principle could impair STAT1 signaling. However, we observed no differences in phosphorylation levels of wildtype STAT1 and STAT $1^{\mathrm{K} 679 \mathrm{Q}}$ (Fig. 3N). Hence, mimicking acetylation of STAT1 at $\mathrm{K}^{410}$ and $\mathrm{K}^{413}$ very specifically counteracts STAT1 signaling.

\section{STAT1 activity is regulated by CBP and GCN5}

Previously, we found that CBP is the HAT responsible for acetylation of STAT1, and that CBP translocates to the cytoplasm in response to IFN- $\alpha$ or HDACi (Krämer et al. 2006). The slow kinetics of HDACi-induced, compared with IFN-induced, acetylation of STAT1 correlates with delayed cytosolic appearance of CBP (data not shown). Since CBP specifically acetylates STAT1 (Krämer et al. 2006; Tang et al. 2007), we asked whether this HAT contributes to the termination of STAT1 signaling. Positive effects of cytosolic CBP/p300 on STAT signaling at the level of the IFNAR were observed in overexpression systems (Tang et al. 2007). This study, however, did not analyze the effect of STAT1 acetylation on IFN-induced signaling, and numerous reports clearly demonstrate that HDAC activity is required for IFN-induced STAT1 activation (Nusinzon and Horvath 2003; Chang et al. 2004; Klampfer et al. 2004; Sakamoto et al. 2004a; Zupkovitz et al. 2006; Vlasáková et al. 2007). Because unphysiological overexpression of the global regulator CBP cannot distinguish between artificially increased basal expression and IFN-induced expression of STAT1 target genes (O'Shea et al. 2005; Lim and Cao 2006), we used RNAi to analyze the role of CBP in STAT1 signaling induced by the physiological stimulus IFN. We generated 293T cells stably expressing shRNAs targeting CBP. Our data demonstrate that silencing of CBP significantly attenuated STAT1 dephosphorylation (Fig. 4A). Accordingly, reporter gene assays and analyses of endogenous ISG15 and UBCH8 levels showed enhanced IFN $\alpha$-triggered STAT1dependent transcription in cells with reduced CBP expression (Fig. 4B-D). These data are consistent with specific acetylation of STAT1 by CBP and enhanced IFN-induced signaling via nonacetylatable STAT1 (Figs. $1 \mathrm{M}, 2 \mathrm{~A}-\mathrm{C}, 3 \mathrm{H})$. 
Figure 3. Phosphorylation and DNA binding of STAT1 are regulated by acetylation. (A) 293T cells were transfected with vectors for HA$\mathrm{STAT1}^{\mathrm{K} 410,413 \mathrm{Q}}(\mathrm{QQ})$ or pcDNA3.1. Cells were treated for 20 min with IFN $\alpha(+)$. STAT1 phosphorylation and expression were analyzed by Western blot. (B) STAT1 phosphorylation was assessed in U3A cells transfected with $\mathrm{STAT}^{\mathrm{K} 410,413 \mathrm{Q}}$ (QQ; $\left.1 \mu \mathrm{g}\right)$ and wild-type STAT1 $(0.5 \mu \mathrm{g})$. Cells were treated for $20 \mathrm{~min}(+) .(C)$ Luciferase assay with a GAS-Luc reporter shows the transcriptional activity of endogenous STAT1 in 293T cells in the presence of increasing amounts of QQ or pcDNA3.1 (3.1; set as 100\% for $24 \mathrm{~h}$ of IFN stimulation). The Western blot shows augmenting QQ expression. (D) Same as in $C$ except that an ISRE-Luc reporter was used. $(E)$ Same as in $A$ except that cells were treated for $24 \mathrm{~h}$ and probed for UBCH8. (F) The ABCD assay shows the DNA binding of endogenous STAT1 from $293 \mathrm{~T}$ cells in the presence of increasing amounts of HA-STAT $1^{\mathrm{K} 410,413 \mathrm{Q}}(\mathrm{QQ} ;+, \mathrm{IFN} \alpha$ for $1 \mathrm{~h})$. (G) $293 \mathrm{~T}$ cells were left untreated (C) or incubated with VPA $(V ; 24 \mathrm{~h})$. Equally treated parallel cultures were exposed to IFN $\alpha$ for $1 \mathrm{~h}$. Lysates were analyzed by ABCD assay. $(H)$ U3A cells were transfected with STAT1 (WT or RR). The induction of IFN $\alpha$-induced ( $8 \mathrm{~h}$ ) expression of the indicated STAT1 target genes in the absence (IFN $\alpha$; individually set as $100 \%$ for each STAT1 variant) or presence of VPA $(1.5 \mathrm{mM})$ during IFN treatment (IFN $\alpha+$ V) or after a $24-\mathrm{h}$ preincubation $(\mathrm{V} / \mathrm{IFN} \alpha)$ was analyzed by quantitative RT-PCR (note the different scales). (I) 293T cells were transfected with HA-tagged STAT1 (WT), STAT1 ${ }^{\mathrm{K} 410,413 \mathrm{Q}}(\mathrm{QQ})$, or STAT1 $^{\text {K410,413R }}(\mathrm{RR})$ and Flag-STAT1. STAT1 homodimerization was assessed by IP against HA, followed by anti-Flag blot (pre, control IgG IP). (J) U3A cells were transfected with STAT1 (WT, QQ, or RR). IPs were done with anti-HA or irrelevant IgG (pre) and probed for STAT1 and endogenous STAT2. $(K)$ U3A cells were transfected with STAT1 (GFP-WT and HA-WT, or GFP-QQ and HA-QQ). IPs were done with an anti-GFP antibody or irrelevant IgG (pre) and probed for STAT1 variants and endogenous STAT2. $(L)$ Confocal immunofluorescence microscopy shows colocalization of wild-type (WT) and pseudo-acetylated STAT1 (QQ) with endogenous STAT2 in U3A cells (numbers state "overlap equation" $\left.\mathrm{r}_{0}\right) .(M)$ U3A cells were transfected with the indicated plasmids for STAT1 (WT/QQ/RR) or pcDNA3.1. STAT2 phosphorylation and expression were analyzed by Western blot $(+$, IFN $\alpha$ for 20 min). ( $N)$ STAT $1^{\mathrm{K} 679 \mathrm{Q}}$ phosphorylation was compared with phosphorylation of wild-type STAT1 and STAT1 ${ }^{\mathrm{K} 410,413 \mathrm{Q}}$ (QQ) in transfected U3A cells treated with IFN $\alpha$ for $20 \mathrm{~min}(+)$.
GCN5 catalyzes the acetylation of histones, but not of STAT1 (Paulson et al. 2002; Kouzarides 2007; Tang et al. 2007). We therefore analyzed the function of this HAT in IFN-induced signaling via an siRNA approach. This experiment showed that ablation of GCN5 decreased the induction of the GAS-reporter and of endogenous UBCH8 (Fig. 4E,F). Degradation or nuclear export of GCN5 cannot, however, explain why HDACi or pretreatment with IFN $\alpha$ inhibit STAT1 signaling, as GCN5 remained stable and nuclear under these conditions
B

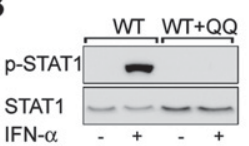

C

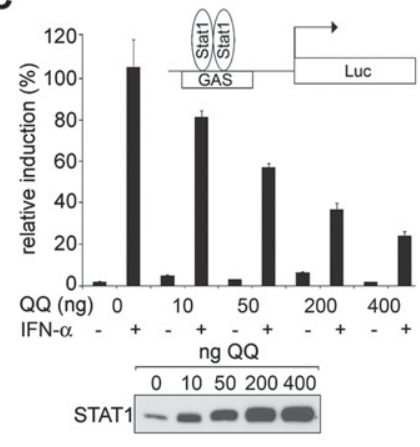

$\mathbf{M}$

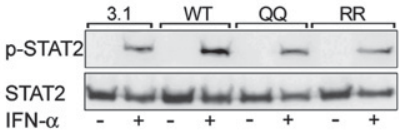

$\mathbf{N}$

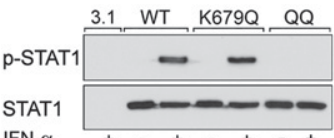

(Supplemental Fig. S2A). Our data demonstrate opposing effects of CBP and GCN5 on IFN-dependent STAT1 signaling. In contrast to GCN5, CBP can negatively regulate STAT1 activity in this context.

\section{HDAC3 catalyzes STAT1 deacetylation}

VPA, which selectively inhibits the class I HDACs HDAC1, HDAC2, HDAC3, and HDAC8, induces STAT1 acetylation (Göttlicher et al. 2001; Krämer et al. 2006). These HDACs are therefore likely candidate deacetylases 
A

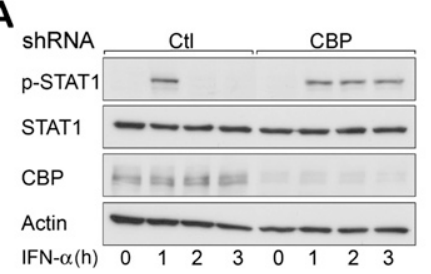

B

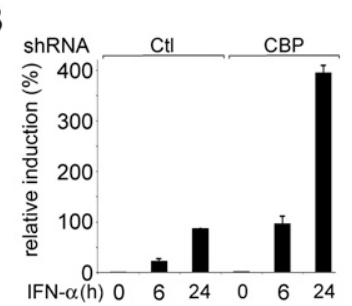

D

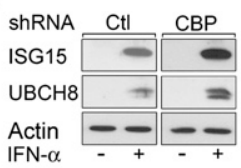

G

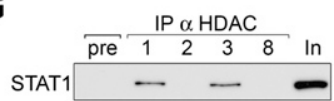

E

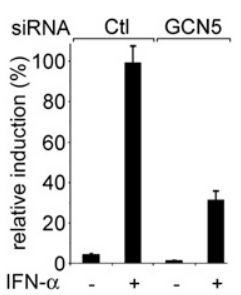

C

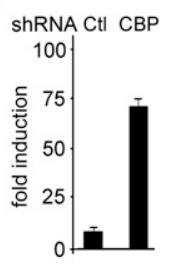

Figure 4. HATs and HDACs control STAT1 acetylation and phosphorylation. (A) 293T cells stably expressing shRNAs against CBP (shRNA CBP) or a nontargeting control vector (shRNA Ctl) were treated with IFN $\alpha$. STAT1 phosphorylation, expression, and efficiency of the CBP knockdown were analyzed by Western blot. $(B)$ Luciferase assay with the GAS-Luc construct in these cells. IFN $\alpha$ was added for 6-24 h (values for shRNA Ctl cells induced with IFN $\alpha$ for 24 $\mathrm{h}$ are set as $100 \%)$. (C) Real-time PCR was performed to analyze ubcH8 expression in 293T cells harboring shRNA Ctl or shRNA CBP. Cells were treated for $8 \mathrm{~h}$ with IFN $\alpha$. (D) Western blot shows induction of UBCH8 and ISG15 in 293T cells bearing shRNA Ctl or shRNA CBP after addition of IFN $\alpha$ for 24 h. (E) Activation of the GAS-Luc reporter after knockdown of GCN5 by siRNAs (ctl, nontargeting siRNA) in 293T cells treated with IFN $\alpha(24 \mathrm{~h}) .(F)$ UBCH8 induction in cells treated as in $D$. The Western blot was probed as indicated. $(G)$ The Western blot demonstrates the interaction of endogenous STAT1 with endogenous HDACs, which were immunoprecipitated from 293T cell lysates. Efficient HDAC depletion was confirmed by Western blot (not shown). $(H)$ Localization of $\mathrm{HDAC1}$ and $\mathrm{HDAC} 3$ in

cytosolic (Cyt) and nuclear fractions (Nuc) prepared from 293T cells. (I) STAT1 acetylation in 293T cells overexpressing CBP and HDAC3 was analyzed by STAT1-IP and anti-acetyllysine Western blot. (J) Same as in I with CBP or siRNAs for HDAC3. (K) STAT1 phosphorylation was analyzed in 293T cells transfected with siRNA against HDAC3 or nontargeting control siRNA. Cells were IFN-treated for 20 min. $(L)$ Same as in E, with siRNAs against HDAC3.

for STAT1. In co-IP experiments with endogenous proteins from 293T cells, STAT1 was recovered in a complex with HDAC1 and HDAC3 (Fig. 4G; Krämer et al. 2006). In contrast to HDAC1, HDAC3 localizes to both, nucleus and cytoplasm, and interacts with STAT1 in both cellular compartments (Fig. 4H; Chang et al. 2004; data not shown). Thus, HDAC3 is the most likely STAT1 deacetylase in the cytosol initiating STAT1 signaling.

Cotransfection experiments confirmed that HDAC3 strongly counteracts CBP-mediated STAT1 acetylation (Fig. 4I). Likewise, siRNA-induced ablation of HDAC3, similar to CBP overexpression, promoted STAT1 acetylation (Fig. 4J). Remarkably, knocking down HDAC3 equally translated into reduced STAT1 phosphorylation and attenuated IFN-dependent transcriptional activation (Fig. 4K,L). Hence, HDAC3 antagonizes STAT1 acetylation, which allows IFN-triggered STAT1 signaling. These observations provide an explanation why cytokine-induced STAT1 target gene expression requires HDAC activity. Our data further reveal that CBP and HDAC3 are the enzymes antagonistically regulating acetylation and ultimately signaling of STAT1.

\section{PTP-dependent inactivation of acetylated STAT1}

Activation by kinase-mediated phosphorylation and attenuation by PTP-mediated dephosphorylation are hallmarks of STAT1 signaling. We noted significant differences in the phosphorylation of STAT1 and STAT $1^{\mathrm{K} 410,413 \mathrm{Q}}$ in vitro and in cells. Although TYK2 catalyzed phosphorylation of both proteins in vitro (Fig. 5A), only wild-type STAT1 was phosphorylated in TYK2transfected U3A cells (Fig. 5B). Notably, application of the general PTP inhibitor vanadate together with IFN $\alpha$ not only maintained phosphorylation of endogenous STAT1 in 293 T cells (Supplemental Fig. S2B), but also permitted phosphorylation and nuclear translocation of STAT $1^{\mathrm{K} 410,413 \mathrm{Q}}$ in U3A and $293 \mathrm{~T}$ cells (Fig. 5C,D; Supplemental Fig. S2C). In response to this treatment, STAT $1^{\mathrm{K} 410,413 \mathrm{Q}}$ even induced endogenous UBCH8 and bound cognate DNA (Fig. 5E,F; Supplemental Fig. S2D). Hence, PTPs antagonize kinase activity and appear to critically mediate STAT1's acetylation-dependent repression.

Since acetylated STAT1 forms a cytosolic complex with NFкB p65 in vitro and in vivo (Krämer et al. 2006; Hayashi et al. 2007), NFkB and IкBs could attenuate STAT1 ${ }^{\mathrm{K} 410,413 \mathrm{Q}}$. However, STAT1 $1^{\mathrm{K} 410,413 \mathrm{Q}}$ remained unresponsive to IFN upon inactivation of $\mathrm{p} 65$ by siRNAs or attenuation of IкBs by TNF $\alpha$ (Fig. 5D,E; Supplemental Fig. S3A). These results, along with the observation that STAT $1^{\mathrm{K} 410,413 \mathrm{Q}}$ and STAT1 interacted equally well with PIAS1, SOCS1, and SUMO1 (Supplemental Fig. S3B), disfavor alternative PTP-independent regulatory mechanisms.

In agreement with these data, STAT1 acetylated via HDACi treatment was phosphorylated and bound to 
DNA after treatment with IFN $\alpha$ and vanadate (Fig. 5G). Likewise, combined application of these stimuli induced phosphorylation of STAT $1^{\mathrm{K} 410 \mathrm{Q}}$ and STAT $1^{\mathrm{K} 413 \mathrm{Q}}$ in U3A cells. Both proteins could then bind GAS DNA as well as GCN5 and induce transcriptional activation (Fig. $5 \mathrm{H}-\mathrm{J})$.

Our data and those from Melén et al. (2001) show that local charge alterations within the STAT1 DBD do not prevent STAT1 signaling per se. Furthermore, STAT1 acetylation site mutants as well as STAT1 acetylated via HDACi are structurally intact and in principle permissive for phosphorylation. Consistent with this, acetylation of STAT1 does not compromise its intracellular localization in the uninduced state (Figs. 1H,J, 3L; Krämer et al. 2006). Acetylation of STAT1, rather, represents a PTP-dependent refractory state of STAT1.

A

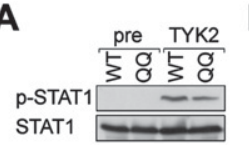

D

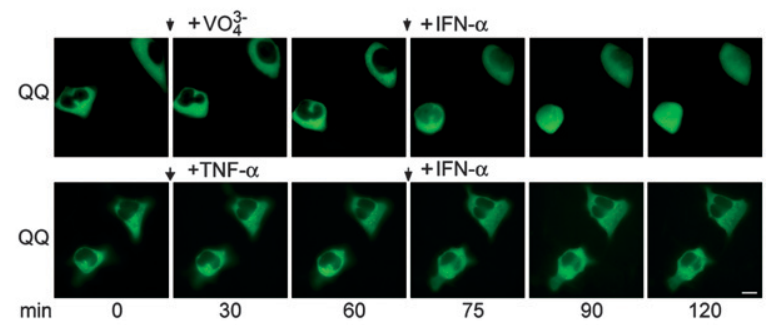

E

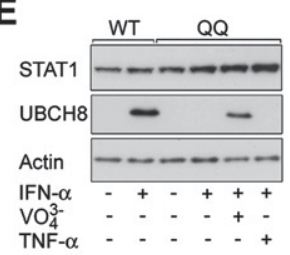

G

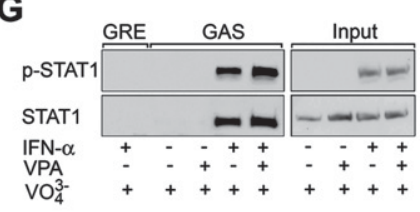

I

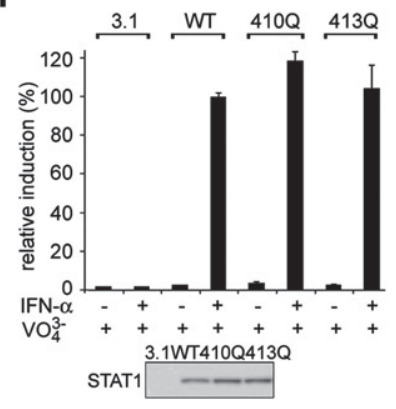

B
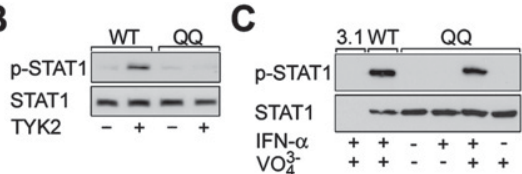

\section{TCP45 binds to acetylated STAT1}

We next investigated which PTPs are relevant for the inactivation of STAT1 following acetylation. SHP2 (SH2containing PTP) and TCP45 are PTPs negatively regulating STAT1 signaling (ten Hoeve et al. 2002; Wu et al. 2002). To clarify their role in the STAT1 phospho-acetyl switch, we generated 293T cells in which PTP levels are stably suppressed by shRNAs. Reporter assays with these cells confirmed that SHP2 and, even more potently, TCP45 suppress endogenous STAT1 signaling (Fig. 6A). IFN-induced reporter gene activation was furthermore unaffected by vanadate treatment in cells bearing shRNAs against SHP2 and TCP45 (data not shown), which supports the view that they are the key PTPs for STAT1.

Since, similar to vanadate treatment, the down-regulation of TCP45 by shRNA rescued STAT1 signaling in the presence of STAT $1^{\mathrm{K} 410,413 \mathrm{Q}}$ (Fig. 6B), we focused on this PTP. If TCP45 prevents IFN $\alpha$-induced phosphorylation of acetylated STAT1, HDACis should not inhibit STAT1 activation in 293T cells with reduced TCP45 levels. Indeed, STAT1 phosphorylation and DNA recognition were unaffected by HDACis in such cells (Fig. 6C). Likewise, IFN $\alpha$ induced phosphorylation and strong nuclear accumulation of wild-type STAT1 and STAT $1^{\mathrm{K} 410,413 \mathrm{Q}}$ in TCP45-depleted U3A cells (Fig. 6D; Supplemental Fig. $\mathrm{S} 3 \mathrm{C})$. In U3A shTCP45 cells, STAT1 $1^{\mathrm{K} 410,413 \mathrm{Q}}$-activated transcription of endogenous STAT1 target genes (Fig.

Figure 5. PTPs inactivate acetylated STAT1. (A) STAT1 (WT) and STAT1 $1^{\mathrm{K} 410,413 \mathrm{Q}}(\mathrm{QQ})$ are phosphorylated by TYK2 in vitro. The Western blot was probed for phosphorylated STAT1 and total STAT1. (B) Transfected TYK2 (50 ng) phosphorylates STAT1 (WT) but not STAT1 ${ }^{\mathrm{K} 410,413 \mathrm{Q}}$ (QQ) in U3A cells. Western blotting was done as in $A .(C)$ U3A cells were transfected with STAT1, STAT1 ${ }^{\mathrm{K} 410,413 \mathrm{Q}}$, or pcDNA3.1. Sodium vanadate $\left(\mathrm{VO}_{4}{ }^{3-}\right)$ had been added for $30 \mathrm{~min}$, and then IFN $\alpha$ was added for $20 \mathrm{~min}$. Western blotting was done as in $A$. $(D)$ U3A cells were transfected with EGFP-STAT1 ${ }^{\mathrm{K} 410,413 \mathrm{Q}}$ and analyzed by live cell time-lapse immunofluorescence. $\mathrm{VO}_{4}{ }^{3-}$ or TNF $\alpha$ and IFN $\alpha$ were added at the time points indicated. (E) UBCH8 induction was analyzed by Western blot in U3A cells transfected with wild-type STAT1 or STAT1 ${ }^{\mathrm{K} 410,413 \mathrm{Q}}$. Cells were exposed to $\mathrm{VO}_{4}{ }^{3-}$ or TNF $\alpha$ and IFN $\alpha$ for $24 \mathrm{~h}$. (F) Lysates from U3A cells transfected with STAT1 or STAT1 ${ }^{\mathrm{K} 410,413 \mathrm{Q}}$ were subjected to $\mathrm{ABCD}$ assay for phospho-STAT1-DNA binding. Cells were incubated with $\mathrm{VO}_{4}{ }^{3-}$ for $30 \mathrm{~min}$ followed by IFN $\alpha$ for $1 \mathrm{~h}$; (GRE) control oligonucleotide. (G) $293 \mathrm{~T}$ cells were incubated with VPA $(\mathrm{V} ; 24 \mathrm{~h})$, then with $\mathrm{VO}_{4}{ }^{3-}$ for $30 \mathrm{~min}$, followed by IFN $\alpha$ for $1 \mathrm{~h}$. Lysates were analyzed for STAT 1 phosphorylation and DNA binding by Western blot and ABCD assay. $(H)$ U3A cells transfected with STAT1 (WT), STAT1 ${ }^{\mathrm{K} 410 \mathrm{Q}}(410 \mathrm{Q})$, $\operatorname{orSTAT}^{\mathrm{K} 413 \mathrm{Q}}$ (413Q) were analyzed for STAT1 phosphorylation and subjected to ABCD assay analyzing STAT1 binding to DNA and to GCN5. Cells were incubated as in $F ;(3.1)$ empty vector pcDNA3.1. (I) U3A cells were transfected as in $H$. Luciferase assay was performed to analyze STAT1-dependent gene induction. The Western blot shows equal expression of STAT1 variants. ( $J$ ) Western blot assessing UBCH8 induction after $24 \mathrm{~h}$ of IFN $\alpha$ plus vanadate treatment in U3A cells transfected as in $I$. 
6E). The knockdown of this PTP equally rendered STAT $1^{\mathrm{K} 410 \mathrm{Q}}$ and $\mathrm{STAT} 1^{\mathrm{K} 413 \mathrm{Q}}$ responsive to IFN $\alpha$ (Fig. $6 \mathrm{~F})$, which triggered transcriptional activation of STAT1 target genes (Fig. 6G,H).

Importantly, co-IP analyses showed that STAT1 mutants mimicking acetylation of $\mathrm{K}^{410,413}$ efficiently bound TCP45 (Fig. 7A). This finding provides a rationale for the unresponsiveness of previously activated, acetylated STAT1 to IFN. Therefore, we studied by immunofluorescence whether IFN $\alpha$ not only induces acetylation of STAT1, but also affects the localization of endogenous TCP45 in intact cells. Indeed, periods of IFN $\alpha$ treatment inducing STAT1 acetylation (Fig. 1A,M) caused colocalization of TCP45 and STAT1, together with cytoplasmic translocation of this PTP (Fig. 7B; Supplemental Fig. S3D). Co-IP analyses further confirmed that STAT1 acetylation via IFN $\alpha$ induces formation of a complex containing STAT1 and TCP45 (Figs.1A, 7C).

Further analyses showed that STAT1 phosphorylation peaks at $\sim 20 \mathrm{~min}$ and starts to cease at $\sim 40 \mathrm{~min}$ of IFN- $\alpha$ treatment. Consistent with the reported nuclear dephosphorylation of STAT1 (Haspel et al. 1996; Haspel and Darnell 1999; ten Hoeve et al. 2002), LMB did not alter this kinetic (Fig. 7D). We performed IP experiments with timed cytosolic and nuclear fractions to analyze the interaction of acetylated STAT1 and TCP45. Data obtained with this approach demonstrate that beginning dephosphorylation of STAT1 correlates with acetylated STAT1 binding to TCP45 in the nucleus. Additionally, there is a time-dependent accumulation of cytosolic TCP45 in a complex with acetylated STAT1 (Fig. 7E).

Finally, we asked for how long acetylation of STAT1 inhibits IFN-induced signaling. For this purpose, we pulsed cells with IFN and chased them to study their ability to reinduce STAT1 phosphorylation. After a chase time of $2 \mathrm{~h}$, we could clearly detect phosphorylated STAT1 (Fig. 7F). Remarkably, the return of STAT1 to restimulation capacity was associated with decreased STAT1 acetylation, loss of CBP binding, and reassociation with HDAC3 (Fig. 7G).

Our interaction studies and functional analyses demonstrate the dynamic regulation of STAT1 via CBP, HDAC3, and TCP45. Hence, these factors are key elements of a phospho-acetyl switch regulating STAT1 activity (Fig. $7 \mathrm{H}$ ).

\section{Discussion}

The molecular mechanisms responsible for STAT acetylation are under intense investigation, and IFN-dependent signaling via STAT1 is a paradigm for a pathway requiring deacetylase activity. We analyzed STAT1 signaling in vitro and in cells using a wide variety of conditions and methods. Our data indicate that a functional phospho-acetyl switch, regulated by an acetylation/deacetylation balance, modulates STAT1 signaling.

We initially reported that acetylated STAT1 inhibits NFкB (Krämer et al. 2006). Now, we demonstrate that acetylation of STAT1 counteracts its own activity. Our findings provide a mechanistic basis for the suspected negative role of acetylation on IFN-dependent signaling (Nusinzon and Horvath 2003; Chang et al. 2004; Klampfer et al. 2004; Sakamoto et al. 2004a; Zupkovitz et al. 2006; Vlasáková et al. 2007).

Both phosphorylation and acetylation are versatile modulators of protein functions and interactions (Schreiber and Bernstein 2002). Cross-talk between serine phosphorylation and lysine methylation has been described for the kinetochore protein DAM1 and the transcription factor p53 (Fischle et al. 2003; Zhang and Dent 2005). Our data identify STAT1 as a signaling molecule subject to an unexpected cross-regulation between phosphorylation and lysine acetylation. IFNinduced phosphorylation promotes nuclear translocation of STAT1, which enables it to interact with the acetyltransferase CBP. Acetylation of STAT1 by CBP correlates with the formation of a STAT1-TCP45 complex, dephosphorylation, and latency of STAT1. We conclude that the highly active PTP TCP45 acts as a "transmission control protein" docking to and inhibiting previously activated STAT1. STAT1 acetylation hence conveys information terminating stimulation and regulating restimulation.

Extensive conformational changes are necessary for STAT1 dephosphorylation. The "pocket" residues $\mathrm{Q}^{340}$, $\mathrm{Q}^{408}$, and $\mathrm{G}^{384}$ are required for spatial reorientation of a parallel to an anti-parallel STAT1 dimer presenting the pY $^{701}$ to TCP45 (Zhong et al. 2005; Mertens et al. 2006). It appears feasible that after initial activation, and once acetylated in the nucleus by CBP, STAT1 is stabilized in its anti-parallel structure providing access for TCP45. Since HDACis inhibit IFN-induced phosphorylation and promote dephosphorylation of STAT1, acetylation of lysines $\mathrm{K}^{410}$ and $\mathrm{K}^{413}$ may facilitate both, disengagement of STAT1 from DNA and presentation to TCP45 (Meyer et al. 2003; Mao et al. 2005; Mertens et al. 2006). Although $\mathrm{K}^{410}$ and $\mathrm{K}^{413}$ provide contacts of STAT1 with the DNA backbone (Chen et al. 1998; Melén et al. 2001), these lysines do not contribute to specific STAT1-DNA contacts, and 12 additional amino acid side chains connect STAT1 with DNA /Chen et al. 1998; Melén et al. 2001). In agreement with this, phosphorylated STAT $1^{\mathrm{K} 410,413 \mathrm{Q}}$ can bind DNA, albeit slightly weaker than the wild type. Consistent with the observation that these residues do not belong to the "pocket" residues required for $\mathrm{N}$-terminal dimerization, mutagenesis of $\mathrm{K}^{410}, \mathrm{~K}^{413}$ does not affect STAT1 dimerization. Furthermore, the activity of STAT $1^{\mathrm{K} 410,413 \mathrm{Q}}$ under conditions in which TCP45 is blocked either by shRNA or vanadate strongly indicates that this protein is structurally intact.

Acetylation of STAT1 within its surface-exposed DBD determines functionally relevant interactions of STAT1 with other regulators of signaling. Since HATs interact with all STATs, acetylation and deacetylation might regulate each of them. Nevertheless, assessing the specific consequences of acetylation requires individual analyses. In the case of STAT1, acetylation clearly acts inhibitorily. In contrast, acetylation seems to affect STAT3 dimerization, and it remains to be determined 
Figure 6. TCP45 inactivates acetylated STAT1. (A) Luciferase assay with a GAS-Luc construct in 293T cells stably expressing shRNAs against SHP2 and TCP45. IFN $\alpha$-induced ( $24 \mathrm{~h}$ ) shRNA Ctl cells are set as $100 \%$. The Western blot shows efficient phosphatase depletion and UBCH8 induction with shorter and longer $\left({ }^{*}\right)$ film exposure. $(B)$ Luciferase assay was performed as in $A$ in the presence of STAT1 ${ }^{\mathrm{K} 410,413 \mathrm{Q}}$ (QQ). (C) $293 \mathrm{~T}$ cells expressing TCP45 shRNA were treated with HDACis [(V) VPA; (T) TSA; (B) sodium butyrate; $(\mathrm{C})$ not treated with HDACi] and 24 $\mathrm{h}$ later with IFN $\alpha$ for $20 \mathrm{~min}(+)$. STAT1 phosphorylation and expression were analyzed. (Right panel) Binding of phosphorylated STAT1 to the GAS oligonucleotide was assessed by ABCD assay and Western blotting; (GRE) control oligonucleotide. (D) U3A cells stably expressing STAT1 (WT) or STAT1 $^{\mathrm{K} 410,413 \mathrm{Q}}$ (QQ) were transfected with TCP45 shRNA for $48 \mathrm{~h}$ and treated with IFN $\alpha$ for $1 \mathrm{~h}(+)$, or $(-)$ left untreated, and analyzed for nuclear translocation of STAT1 by Immunofluorescence microscopy. (Right panel) Equally transfected U3A cells were analyzed for phosphorylation and expression of STAT1. (E) U3A cells transfected with STAT $1^{\mathrm{K} 410,413 \mathrm{Q}}$ and TCP45 shRNA. IFN $\alpha$ was added for $24 \mathrm{~h}$ $(+)$. Expression of STAT1 and its target genes UBCH8 and ISG15, and shRNA efficiency were analyzed by Western blot. (F) U3A cells transfected with TCP45 shRNA and wildtype STAT1 (WT), STAT1 ${ }^{\mathrm{K} 410 \mathrm{Q}}, \mathrm{STAT}^{\mathrm{K} 413 \mathrm{Q}}$, or pcDNA3.1 were treated with IFN $\alpha(1 \mathrm{~h})$.
A

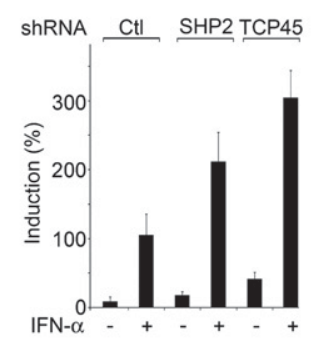

B

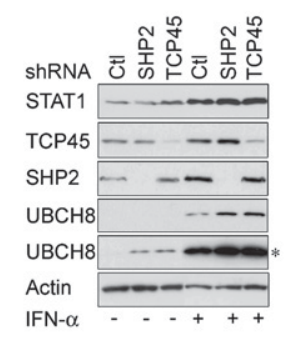

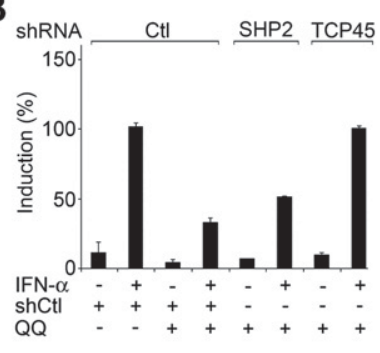

C

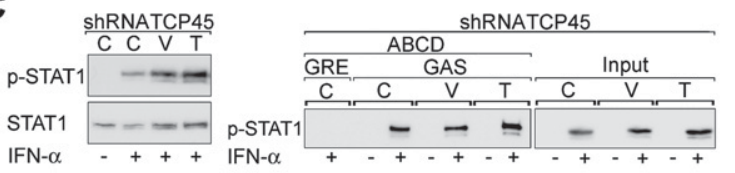

D

E
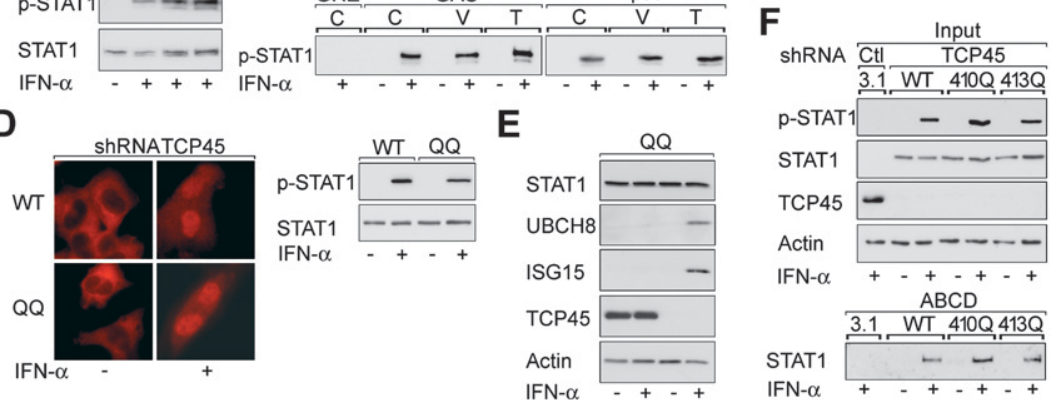

G

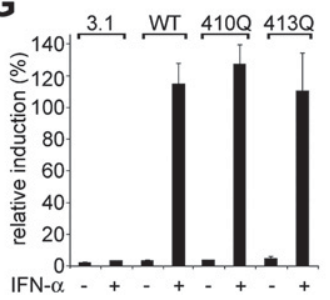

H

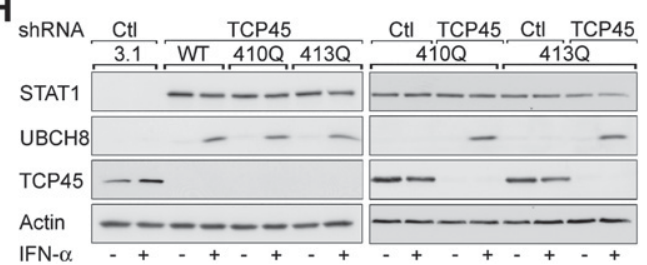

(Top panel) STAT1 phosphorylation, expression, and shRNA efficiency were analyzed by Western blotting. (Bottom panel) Binding of STAT1 to GAS-DNA was analyzed via ABCD assay (cf. Fig. 2E-I). (G) U3A cells transfected as in $F$ were analyzed for GAS-Luc activation (induction by wild-type STAT1 set as $100 \%$ ). Cells were incubated with IFN $\alpha$ for $24 \mathrm{~h}$. (H) Same as in E, analysis of STAT1 (WT), $\mathrm{STAT}^{\mathrm{K} 410 \mathrm{Q}}$, and STAT $1^{\mathrm{K} 413 \mathrm{Q}}$.

how STAT3 signaling is terminated (Yuan et al. 2005). Acetylation of STAT3 residues corresponding to $\mathrm{K}^{410}$ and $\mathrm{K}^{413}$ in STAT1 can be ruled out, as these residues are arginines in STAT3 (Supplemental Fig. S3E), which could well explain why HDACis do not inhibit STAT3. Moreover, the fact that STAT1 acetylation does not suppress STAT2 function is consistent with the observation that STAT2 is inactivated neither by TCP45 nor by HDACis (Sakamoto et al. 2004b; Vlasáková et al. 2007).

Equal to phosphorylation, acetylation does not necessarily enhance gene activation, and the physiological consequences of histone versus nonhistone protein modification by HATs and HDACs are clearly different (Schreiber and Bernstein 2002; Yang 2004). Reminiscent of data collected for STAT2 (Paulson et al. 2002), our results support that GCN5 is required for IFN-induced STAT1/STAT2 signaling. In contrast to CBP, GCN5 catalyzes the acetylation of histones, but not of STAT1 (Paulson et al. 2002; Tang et al. 2007). In agreement with this finding, HDACis promote IFN-induced signaling, but only if IFN-dependent gene induction is evoked by a nonacetylatable STAT1 molecule. CBP and GCN5 even show opposing effects, as CBP-mediated acetylation of STAT1 within its DBD is dominant over STAT1 activation. Our results provide a rationale for the negative role of STAT1 acetylation on IFN signaling. They elucidate a novel, specific role of CBP, which is increasingly appreciated as a nonhistone protein acetyltransferase and a negative regulator of gene expression (Munshi et al. 1998; Zhang and Dent 2005). In agreement with several studies (Nusinzon and Horvath 2003; Chang et al. 2004; Klampfer et al. 2004; Sakamoto et al. 2004a; Zupkovitz et al. 2006; Vlasáková et al. 2007), our data demonstrate that CBP induces STAT1 acetylation and suppresses IFNdependent activation. Therefore, acetylation of STAT1 via CBP dominantly restricts the duration of IFN signaling in human cells responsive to this cytokine.

A very attractive hypothesis is that STAT1 acetylation acts as a "memory mark" designating previously activated STAT1. Within a "STAT1 modification code," TCP45 apparently reads out acetylation of this transcription factor. Feed-forward mechanisms for STAT1 acetylation promoting association with TCP45 might be established by the CBP bromodomain recognizing 
A

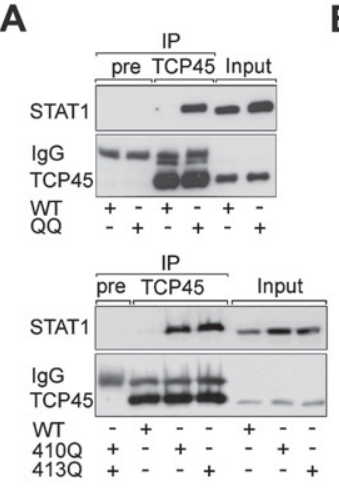

D

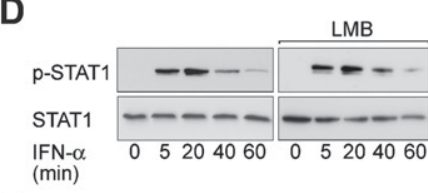

F

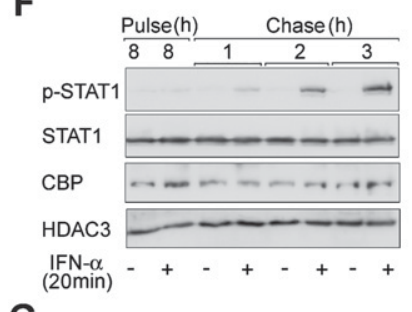

G

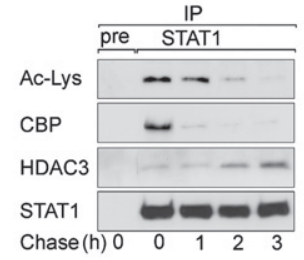

B

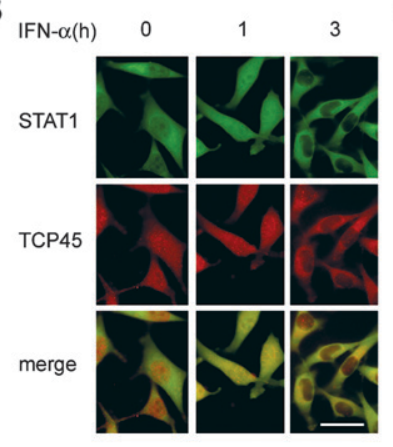

C
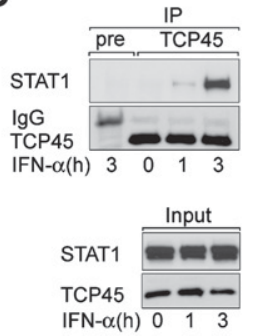

E

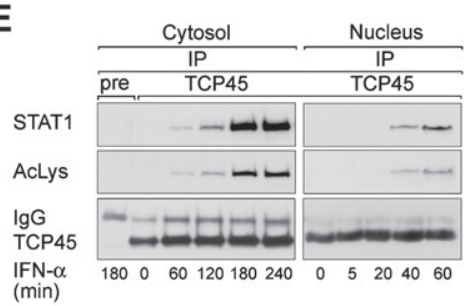

H

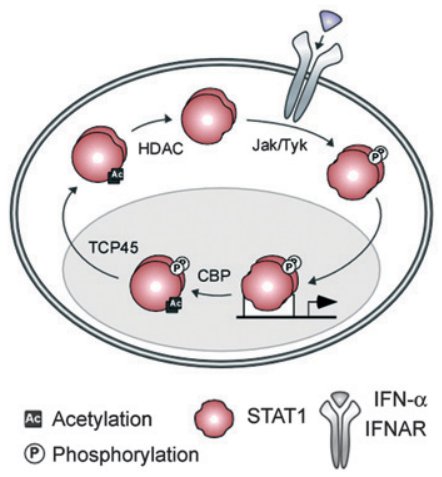

Figure 7. Acetylation of STAT1 recruits TCP45 terminating the IFN signal. (A) U3A cells were transfected with TCP45 substrate trapping mutants TCP45 ${ }^{\mathrm{C} 216 \mathrm{~S} / \mathrm{D} 182 \mathrm{~A}}$. Anti-TCP45 precipitates were analyzed for co-IP of STAT1 or its $\mathrm{K}^{410}$ / $\mathrm{K}^{413}$ acetylation site mutants (QQ/410Q/413Q; [pre] preimmune IP) and efficient precipitation of TCP45. (B) Immunofluorescence analysis of HeLa cells analyzing dynamic localization of endogenous STAT1 and endogenous TCP45 after IFN $\alpha$ stimulation. Bar, $50 \mu \mathrm{m}$. (C) TCP45 $5^{\mathrm{C} 216 \mathrm{~S} / \mathrm{D} 182 \mathrm{~A}} \mathrm{IPs}$ from $293 \mathrm{~T}$ cells treated with IFN $\alpha$ as in $B$ were subjected to Western blot against STAT1 and TCP45. (D) 293T cells were stimulated with IFN $\alpha$ for 0-60 min. STAT1 phosphorylation and STAT1 expression, in the absence or presence of LMB, were monitored by Western blot. (E) TCP45 ${ }^{\mathrm{C} 216 \mathrm{~S} /}$ D182A IPs from cytosolic and nuclear extracts from 293 T cells treated with IFN $\alpha$ for the time periods indicated were subjected to Western blotting against STAT1, acetyl-lysine, and TCP45. (F) $293 \mathrm{~T}$ cells were incubated with IFN $\alpha$ for $8 \mathrm{~h}$ (Pulse). After removal of IFN $\alpha$, cells were retreated with IFN $\alpha$ for $20 \mathrm{~min}(+)$ or not restimulated $(-)$ at 1 -h intervals. The presence of phosphorylated STAT1, STAT1, CBP, and HDAC3 was determined by Western blot. (G) STAT1 IPs were done from the same lysates as in F. STAT1 acetylation and precipitation, and binding of CBP and HDAC3 to STAT1 was determined 1-3 $\mathrm{h}$ after removal of IFN $\alpha$ (Chase). (H) Model illustrating the dynamic modification of STAT1. A phospho-acetyl switch inhibits STAT1 upon its acetylation-dependent recruitment of TCP45 following activation by IFN. STAT1 homodimers serve as the example.
$\mathrm{N}^{\varepsilon}$-acetylated proteins, the IFN-induced cytosolic translocation of CBP, and the reduced interaction of acetylated STAT1 with HDACs (Yang 2004; Krämer et al. 2006; Tang et al. 2007). In addition, dephosphorylated antiparallel STAT1 dimers remain intact and exit to the cytoplasm, tethered via their $\mathrm{N}$-terminal domains (Mertens et al. 2006). Upon nuclear export, dimers or even oligomers of STAT1 (Gupta et al. 1996; Stancato et al. 1996; Vinkemeier and Meyer 2005; Mertens et al. 2006) within a complex containing even a limited number of acetylated STAT1 molecules, bound to CBP and TCP45, can counteract activation of the STAT1 pool. Via such a mechanism, unnecessary activation, energyconsuming degradation, and a potential loss of cytoplasmic functions of STAT1 is prevented (Krämer et al. 2006; Lim and Cao 2006; Kim and Lee 2007). Termination of STAT1 acetylation, via dissociation of CBP and association of HDAC3, in turn shifts the balance to permissiveness for restimulation. Deacetylation of STAT1 by HDACs may provide a molecular switch to restore inducible STAT1 in the cytoplasm, which would close the cycle of STAT1 activation and inactivation (Fig. 7H). Such precise and dynamic acetylation/deacetylation-depen- dent regulatory circuits may have evolved to adjust cytokine-induced gene expression rapidly and economically in vivo.

In addition, both transcription factors, STAT1 as well as $\mathrm{NF \kappa B}$, induce inflammatory mediators contributing to inflammatory diseases, such as rheumatoid arthritis or Crohn's disease, STAT1 acetylation may hence be a central mechanism by which HDACis ameliorate pathophysiological settings with repeatedly released large amounts of proinflammatory cytokines (Blanchard and Chipoy 2005).

\section{Materials and methods}

Cell lines, transfections, microscopy, drugs, and chemicals

Cells were maintained as described (Krämer et al. 2003, 2006). Transfections were done with PEI (Sigma, for 293T) or Lipofectamine (Invitrogen; as recommended). Unless stated otherwise, 1 $\mu \mathrm{g}$ DNA/12-well or $5 \mu \mathrm{g}$ DNA/10-cm plate were transfected, and cells were harvested $48 \mathrm{~h}$ later. Stable cell lines were generated with G418 $(500 \mu \mathrm{g} / \mathrm{mL})$ or Puromycin $(2 \mu \mathrm{g} / \mathrm{mL})$. Immunofluorescence staining and image analysis of cells were performed as in Krämer et al. (2006). 
Colocalization coefficients represent "overlap equation" (Krämer et al. 2008a):

$$
\mathrm{r}_{0}=\sum \frac{\left(\mathrm{R}_{\mathrm{i}} \mathrm{G}_{\mathrm{i}}\right)}{\sqrt{\sum \mathrm{R}_{\mathrm{i}}^{2} \sum \mathrm{G}_{\mathrm{i}}^{2}}}
$$

Drugs and chemicals were purchased as in Krämer et al. (2006, $2008 \mathrm{a}, \mathrm{b})$. If stated, cells were incubated with $10^{3} \mathrm{U}$ of IFN $\alpha, 50$ $\mathrm{ng} / \mathrm{mL}$ TNF $\alpha, 10 \mathrm{ng} / \mathrm{mL}$ LMB, $10 \mu \mathrm{g} / \mathrm{mL}$ Cycloheximide, $1 \mu \mathrm{g} /$ $\mathrm{mL}$ Actinomycin D, $20 \mu \mathrm{M}$ MG-132, or HDACi [(VPA) $1.5 \mathrm{mM}$ VPA; (TSA) $30 \mathrm{nM}$ TSA; sodium butyrate: $1.5 \mathrm{mM}$ ] for time periods indicated in the figure legends. Vanadate was used at concentrations of $0.1 \mathrm{mM}$ for $24-\mathrm{h}$ incubations and at $1 \mathrm{mM}$ for shorter treatments.

Preparation of cell lysates, IP, pull-down, immunoblotting and $A B C D$ (avidin-biotin-coupled DNA) assay

These techniques were carried out as described (Sekimoto et al. 1997; Krämer et al. 2003, 2006, 2008b). Inputs represent 10\% of lysates used.

\section{Luciferase reporter assays and quantitative PCR}

In all luciferase assays (Göttlicher et al. 2001; Krämer et al. 2006), $24 \mathrm{~h}$ after transfection, $10^{3} \mathrm{U}$ of IFN $\alpha$ was added for 6-24 h. Assays were performed in triplicate and normalized to $\beta$-galactosidase activity. The data shown are representative for at least two independent experiments. For detailed transfection schemes, see the Supplemental Material.

Total RNA was isolated using Illustra RNAspin (GE Healthcare). cDNAs were synthesized with the RT-System (Promega). cDNAs were subjected to one-step real-time PCR in an IQ5 cycler (Bio-Rad) using SYBR Green (Abgene) and fluorescein (annealing temperature: $63^{\circ} \mathrm{C}$ ). Data are $\Delta \Delta-\mathrm{Ct}$ values (unstimulated/stimulated samples) normalized to $18 \mathrm{~S}$ rRNA (Krämer et al. 2008b).

Antibodies, sequences for quantitative PCR and gene silencing, and in vitro phosphorylation assay

Details are provided in the Supplemental Material.

\section{Acknowledgments}

We thank S. Müller, S. Schneider, J. Müller, and A. Bäurle for excellent assistance, and C. Liebmann and all members of the Heinzel laboratory for helpful discussion. F. Grosse, M. Truss, N. Tonks, B. Markova, C. Horvath, I. Behrmann, P. Möller, Y. Yoneda, G. Stark, C. Glass, J. Krolewski, and J. Darnell kindly provided material. This work was supported by funding through DFG SFB 604.

\section{References}

Blanchard, F. and Chipoy, C. 2005. Histone deacetylase inhibitors: New drugs for the treatment of inflammatory diseases? Drug Discov. Today 10: 197-204.

Braunstein, J., Brutsaert, S., Olson, R., and Schindler, C. 2003. STATs dimerize in the absence of phosphorylation. J. Biol. Chem. 278: 34133-34140.

Chang, H.M., Paulson, M., Holko, M., Rice, C.M., Williams, B.R., Marie, I., and Levy, D.E. 2004. Induction of interferonstimulated gene expression and antiviral responses require protein deacetylase activity. Proc. Natl. Acad. Sci. 101:95789583.
Chen, X., Vinkemeier, U., Zhao, Y., Jeruzalmi, D.,Darnell Jr., J.E., and Kuriyan, J. 1998. Crystal structure of a tyrosine phosphorylated STAT-1 dimer bound to DNA. Cell 93: 827839.

Christova, R., Jones, T., Wu, P.J., Bolzer, A., Costa-Pereira, A.P., Watling, D., Kerr, I.M., and Sheer, D. 2007. P-STAT1 mediates higher-order chromatin remodelling of the human MHC in response to IFNg. I. Cell Sci. 120: 3262-3270.

Dao, C.T. and Zhang, D.E. 2005. ISG15: A ubiquitin-like enigma. Front. Biosci. 10: 2701-2722.

Fischle, W., Wang, Y., and Allis, C.D. 2003. Binary switches and modification cassettes in histone biology and beyond. Nature 425: 475-479.

Göttlicher, M., Minucci, S., Zhu, P., Krämer, O.H., Schimpf, A., Giavara, S., Sleeman, J.P., Lo, C.F., Nervi, C., Pelicci, P.G., et al. 2001. Valproic acid defines a novel class of HDAC inhibitors inducing differentiation of transformed cells. EMBO T. 20: 6969-6978.

Gupta, S., Yan, H., Wong, L.H., Ralph, S., Krolewski, J., and Schindler, C. 1996. The SH2 domains of Stat1 and Stat2 mediate multiple interactions in the transduction of IFNa signals. EMBO J. 15: 1075-1084.

Haspel, R.L. and Darnell Jr., J.E. 1999. A nuclear protein tyrosine phosphatase is required for the inactivation of Stat1. Proc. Natl. Acad. Sci. 96: 10188-10193.

Haspel, R.L., Salditt-Georgieff, M., and Darnell Jr., J.E. 1996. The rapid inactivation of nuclear tyrosine phosphorylated Stat1 depends upon a protein tyrosine phosphatase. EMBO I. 15: 6262-6268.

Hayashi, T., Ishida, Y., Kimura, A., Iwakura, Y., Mukaida, N., and Kondo, T. 2007. IFN-g protects cerulein-induced acute pancreatitis by repressing NF-к B activation. I. Immunol. 178: 7385-7394.

Ihle, J.N. 2001. The Stat family in cytokine signaling. Curr. Opin. Cell Biol. 13: 211-217.

Kim, H.S. and Lee, M.S. 2007. STAT1 as a key modulator of cell death. Cell. Signal. 19: 454-465.

Klampfer, L., Huang, J., Swaby, L.A., and Augenlicht, L. 2004. Requirement of histone deacetylase activity for signaling by STAT1. J. Biol. Chem. 279: 30358-30368.

Kouzarides, T. 2007. Chromatin modifications and their function. Cell 128: 693-705.

Krämer, O.H., Zhu, P., Ostendorff, H.P., Golebiewski, M., Tiefenbach, J., Peters, M.A., Brill, B., Groner, B., Bach, I., Heinzel, T., et al. 2003. The histone deacetylase inhibitor valproic acid selectively induces proteasomal degradation of HDAC2. EMBO T. 22: 3411-3420.

Krämer, O.H., Baus, D., Knauer, S.K., Stein, S., Jager, E., Stauber, R.H., Grez, M., Pfitzner, E., and Heinzel, T. 2006. Acetylation of Stat 1 modulates NF-кB activity. Genes \& Dev. 20: 473485.

Krämer, O.H., Knauer, S.K., Zimmermann, D., Stauber, R.H., and Heinzel, T. 2008a. Histone deacetylase inhibitors and hydroxyurea modulate the cell cycle and cooperatively induce apoptosis. Oncogene 27: 732-740.

Krämer, O.H., Müller, S., Buchwald, M., Reichardt, S., and Heinzel, T. 2008b. Mechanism for ubiquitylation of the leukemia fusion proteins AML1-ETO and PML-RARa. FASEB J. 22: 1369-1379.

Lim, C.P. and Cao, X. 2006. Structure, function, and regulation of STAT proteins. Mol. Biosyst. 2: 536-550.

Mao, X., Ren, Z., Parker, G.N., Sondermann, H., Pastorello, M.A., Wang, W., McMurray, J.S., Demeler, B., Darnell Jr., J.E., and Chen, X. 2005. Structural bases of unphosphorylated STAT1 association and receptor binding. Mol. Cell 17: 761771. 
Melén, K., Kinnunen, L., and Julkunen, I. 2001. Arginine/lysinerich structural element is involved in interferon-induced nuclear import of STATs. J. Biol. Chem. 276: 16447-16455.

Mertens, C., Zhong, M., Krishnaraj, R., Zou, W., Chen, X., and Darnell Jr., J.E. 2006. Dephosphorylation of phosphotyrosine on STAT1 dimers requires extensive spatial reorientation of the monomers facilitated by the N-terminal domain. Genes \& Dev. 20: 3372-3381.

Meyer, T., Marg, A., Lemke, P., Wiesner, B., and Vinkemeier, U. 2003. DNA binding controls inactivation and nuclear accumulation of the transcription factor Stat1. Genes \& Dev. 17: 1992-2005.

Munshi, N., Merika, M., Yie, J., Senger, K., Chen, G., and Thanos, D. 1998. Acetylation of HMG I(Y) by CBP turns off IFN b expression by disrupting the enhanceosome. Mol. Cell 2: 457-467.

Nusinzon, I. and Horvath, C.M. 2003. Interferon-stimulated transcription and innate antiviral immunity require deacetylase activity and histone deacetylase 1. Proc. Natl. Acad. Sci. 100: 14742-14747.

Nyman, T.A., Matikainen, S., Sareneva, T., Julkunen, I., and Kalkkinen, N. 2000. Proteome analysis reveals ubiquitinconjugating enzymes to be a new family of interferon-aregulated genes. Eur. J. Biochem. 267: 4011-4019.

Okumura, A., Pitha, P.M., and Harty, R.N. 2008. ISG15 inhibits Ebola VP40 VLP budding in an L-domain-dependent manner by blocking Nedd4 ligase activity. Proc. Natl. Acad. Sci. 105: 3974-3979.

O'Shea, J.J., Kanno, Y., Chen, X., and Levy, D.E. 2005. Cell signaling. Stat acetylation-A key facet of cytokine signaling? Science 307: 217-218.

Paulson, M., Press, C., Smith, E., Tanese, N., and Levy, D.E. 2002. IFN-stimulated transcription through a TBP-free acetyltransferase complex escapes viral shutoff. Nat. Cell Biol. 4: 140-147.

Pfeffer, L.M., Kim, J.G., Pfeffer, S.R., Carrigan, D.J., Baker, D.P., Wei, L., and Homayouni, R. 2004. Role of nuclear factor- $\mathrm{kB}$ in the antiviral action of interferon and interferon-regulated gene expression. J. Biol. Chem. 279: 31304-31311.

Platanias, L.C. 2005. Mechanisms of type-I- and type-II-interferonmediated signalling. Nat. Rev. Immunol. 5: 375-386.

Ramsauer, K., Farlik, M., Zupkovitz, G., Seiser, C., Kroger, A., Hauser, H., and Decker, T. 2007. Distinct modes of action applied by transcription factors STAT1 and IRF1 to initiate transcription of the IFN-g-inducible gbp2 gene. Proc. Natl. Acad. Sci. 104: 2849-2854.

Sakamoto, S., Potla, R., and Larner, A.C. 2004a. Histone deacetylase activity is required to recruit RNA polymerase II to the promoters of selected interferon-stimulated early response genes. J. Biol. Chem. 279: 40362-40367.

Sakamoto, S., Qin, J., Navarro, A., Gamero, A., Potla, R., Yi, T., Zhu, W., Baker, D.P., Feldman, G., and Larner, A.C. 2004b. Cells previously desensitized to type 1 interferons display different mechanisms of activation of stat-dependent gene expression from naive cells. J. Biol. Chem. 279: 3245-3253.

Schreiber, S.L. and Bernstein, B.E. 2002. Signaling network model of chromatin. Cell 111: 771-778.

Sekimoto, T., Imamoto, N., Nakajima, K., Hirano, T., and Yoneda, Y. 1997. Extracellular signal-dependent nuclear import of Statl is mediated by nuclear pore-targeting complex formation with NPI-1, but not Rch1. EMBO J. 16: 70677077.

Stancato, L.F., David, M., Carter-Su, C., Larner, A.C., and Pratt, W.B. 1996. Preassociation of STAT1 with STAT2 and STAT3 in separate signalling complexes prior to cytokine stimulation. J. Biol. Chem. 271: 4134-4137.
Stark, G.R. 2007. How cells respond to interferons revisited: From early history to current complexity. Cytokine Growth Factor Rev. 18: 419-423.

Tang, X., Gao, J.S., Guan, Y.J., McLane, K.E., Yuan, Z.L., Ramratnam, B., and Chin, Y.E. 2007. Acetylation-dependent signal transduction for type I interferon receptor. Cell 131: 93-105.

ten Hoeve, J., de Jesus Ibarra-Sanchez, M., Fu, Y., Zhu, W., Tremblay, M., David, M., and Shuai, K. 2002. Identification of a nuclear Stat1 protein tyrosine phosphatase. Mol. Cell. Biol. 22: 5662-5668.

Torchia, J., Rose, D.W., Inostroza, J., Kamei, Y., Westin, S., Glass, C.K., and Rosenfeld, M.G. 1997. The transcriptional coactivator $\mathrm{p} / \mathrm{CIP}$ binds $\mathrm{CBP}$ and mediates nuclear-receptor function. Nature 387: 677-684.

Vinkemeier, U. and Meyer, T. 2005. Antiviral activity of oligomerization-deficient Stat1. Genome Inform. 16: 44-48.

Vlasáková, J., Nováková, Z., Rossmeislová, L., Kahle, M., Hozák, P., and Hodný, Z. 2007. Histone deacetylase inhibitors suppress IFNa-induced up-regulation of promyelocytic leukemia protein. Blood 109: 1373-1380.

Wu, T.R., Hong, Y.K., Wang, X.D., Ling, M.Y., Dragoi, A.M., Chung, A.S., Campbell, A.G., Han, Z.Y., Feng, G.S., and Chin, Y.E. 2002. SHP-2 is a dual-specificity phosphatase involved in Statl dephosphorylation at both tyrosine and serine residues in nuclei. J. Biol. Chem. 277: 47572-47580.

Yang, X.J. 2004. Lysine acetylation and the bromodomain: A new partnership for signaling. Bioessays 26: 1076-1087.

Yuan, Z.L., Guan, Y.J., Chatterjee, D., and Chin, Y.E. 2005. Stat3 dimerization regulated by reversible acetylation of a single lysine residue. Science 307: 269-273.

Zhang, K. and Dent, S.Y. 2005. Histone modifying enzymes and cancer: Going beyond histones. J. Cell. Biochem. 96: 11371148.

Zhang, J.J., Vinkemeier, U., Gu, W., Chakravarti, D., Horvath, C.M., and Darnell Jr., J.E. 1996. Two contact regions between Stat 1 and $\mathrm{CBP} / \mathrm{p} 300$ in interferon g signaling. Proc. Natl. Acad. Sci. 93: 15092-15096.

Zhong, M., Henriksen, M.A., Takeuchi, K., Schaefer, O., Liu, B., ten Hoeve, J., Ren, Z., Mao, X., Chen, X., Shuai, K., et al. 2005. Implications of an antiparallel dimeric structure of nonphosphorylated STAT1 for the activation-inactivation cycle. Proc. Natl. Acad. Sci. 102: 3966-3971.

Zupkovitz, G., Tischler, J., Posch, M., Sadzak, I., Ramsauer, K., Egger, G., Grausenburger, R., Schweifer, N., Chiocca, S., Decker, T., et al. 2006. Negative and positive regulation of gene expression by mouse histone deacetylase 1. Mol. Cell. Biol. 26: 7913-7928. 


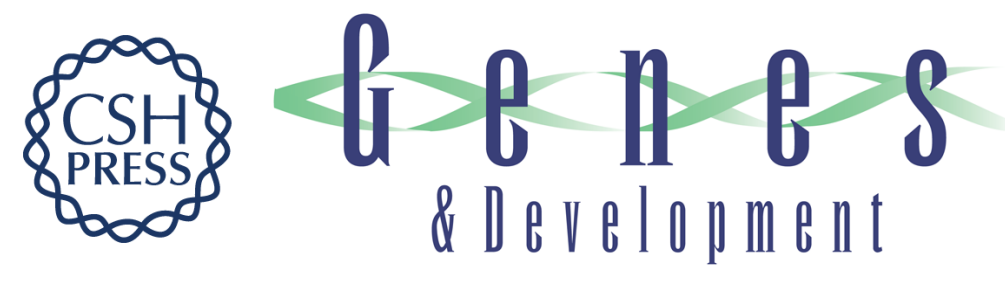

\section{A phosphorylation-acetylation switch regulates STAT1 signaling}

Oliver H. Krämer, Shirley K. Knauer, Georg Greiner, et al.

Genes Dev. 2009, 23:

Access the most recent version at doi:10.1101/gad.479209

Supplemental http://genesdev.cshlp.org/content/suppl/2009/01/27/23.2.223.DC1
Material

References This article cites 52 articles, 28 of which can be accessed free at: http://genesdev.cshlp.org/content/23/2/223.full.html\#ref-list-1

License

Email Alerting Receive free email alerts when new articles cite this article - sign up in the box at the top Service right corner of the article or click here.

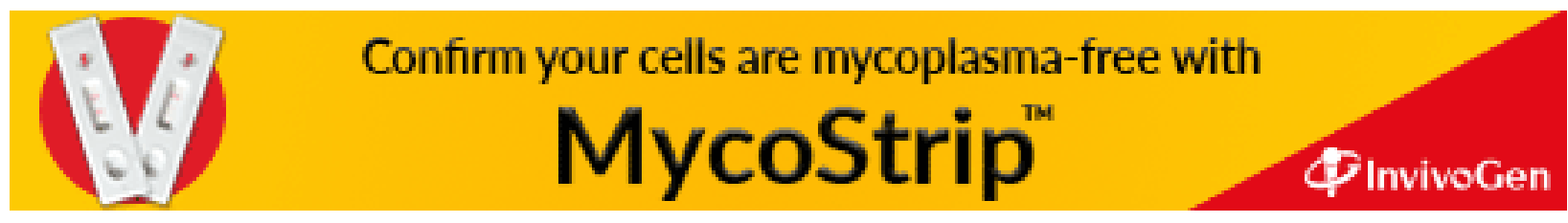

